\title{
Cerebellum in levodopa-induced dyskinesias: the unusual suspect in the motor network
}

\section{Asha Kishore $^{1 *}$ and Traian Popa ${ }^{2}$}

${ }^{1}$ Department of Neurology, Comprehensive Care Centre for Movement Disorders, Sree Chitra Tirunal Institute for Medical Sciences and Technology, Kerala, India

${ }^{2}$ Centre de Neuroimagerie de Recherche (CENIR), Institut du Cerveau et de la Moelleepiniere (ICM), Paris, France

\section{Edited by:}

Antonio Cerasa, Institute of Bioimaging and Molecular

Physiology-CNR, Italy

\section{Reviewed by:}

Giacomo Koch, IRCCS Santa Lucia

Foundation, Italy

Marco Molinari, IRCCS Santa Lucia

Foundation, Italy

Silvia Clausi, IRCCS Santa Lucia

Foundation, Italy

*Correspondence:

Asha Kishore, Department of Neurology, Comprehensive Care

Centre for Movement Disorders, Sree Chitra Tirunal Institute for Medical

Sciences and Technology (SCTIMST),

Kerala 695011, India

e-mail: asha@sctimst.ac.in
The exact mechanisms that generate levodopa-induced dyskinesias (LID) during chronic levodopa therapy for Parkinson's disease (PD) are not yet fully established. The most widely accepted theories incriminate the non-physiological synthesis, release and reuptake of dopamine generated by exogenously administered levodopa in the striatum, and the aberrant plasticity in the cortico-striatal loops. However, normal motor performance requires the correct recruitment of motor maps. This depends on a high level of synergy within the primary motor cortex (M1) as well as between M1 and other cortical and subcortical areas, for which dopamine is necessary. The plastic mechanisms within $M 1$, which are crucial for the maintenance of this synergy, are disrupted both during "OFF" and dyskinetic states in PD. When tested without levodopa, dyskinetic patients show loss of treatment benefits on long-term potentiation and long-term depression-like plasticity of the intracortical circuits. When tested with the regular pulsatile levodopa doses, they show further impairment of the M1 plasticity, such as inability to depotentiate an already facilitated synapse and paradoxical facilitation in response to afferent input aimed at synaptic inhibition. Dyskinetic patients have also severe impairment of the associative, sensorimotor plasticity of M1 attributed to deficient cerebellar modulation of sensory afferents to M1. Here, we review the anatomical and functional studies, including the recently described bidirectional connections between the cerebellum and the basal ganglia that support a key role of the cerebellum in the generation of LID. This model stipulates that aberrant neuronal synchrony in PD with LID may propagate from the subthalamic nucleus to the cerebellum and "lock" the cerebellar cortex in a hyperactive state. This could affect critical cerebellar functions such as the dynamic and discrete modulation of M1 plasticity and the matching of motor commands with sensory information from the environment during motor performance. We propose that in dyskinesias, M1 neurons have lost the ability to depotentiate an activated synapse when exposed to acute pulsatile, non-physiological, dopaminergic surges and become abnormally receptive to unfiltered, aberrant, and non-salient afferent inputs from the environment. The motor program selection in response to such non-salient and behaviorally irrelevant afferent inputs would be abnormal and involuntary. The motor responses are worsened by the lack of normal subcortico-cortical inputs from cerebellum and basal ganglia, because of the aberrant plasticity at their own synapses. Artificial cerebellar stimulation might help re-establish the cerebellar and basal ganglia control over the non-salient inputs to the motor areas during synaptic dopaminergic surges.

Keywords: levodopa-induced dyskinesias, dopamine, Parkinson's disease, plasticity, motor cortex, cerebellum, basal ganglia

\section{INTRODUCTION}

In spite of being the most efficacious drug for the relief of motor symptoms of Parkinson's disease (PD), L-3,4dihydroxyphenylalanine (also known as levodopa) almost invariably generates disabling involuntary movements. Levodopainduced dyskinesias (LID) seldom occur with the first dose of levodopa, but chronic exposure to the drug results in LID in 20 $30 \%$ of PD patients in $\sim 2$ years and in $80 \%$ within 5 years (1). The risk to develop LID is enhanced by younger age, longer durations of disease and levodopa treatment, greater disease severity
(1), higher levodopa dose (2), genetic etiology of the disease (35) and genetic variability in the dopamine metabolizing enzymes (6), dopamine receptor and transporter isoforms (7-9), and brain derived neurotrophic factor (10).

Based on the timing of their appearance in a levodopa cycle, LID are termed as "peak-dose dyskinesia" or "biphasic dyskinesia." Peak-dose dyskinesias are associated with high plasma concentrations of levodopa (11) and the maximum reduction in Parkinsonian signs. Biphasic dyskinesias appear just before the beginning and the end of the relief period of the Parkinsonian 
signs, disappear in the phase of maximum clinical response, and occur below a critical, low level of plasma levodopa (12). Peak-dose dyskinesias are often choreic and seldom pure dystonic movements. Biphasic dyskinesias are stereotyped, repetitive, dystonic movements that are usually confined to the legs, and may cooccur with Parkinsonian signs elsewhere in the body. Dystonic movements can also occur in patients not exposed to levodopa and their presence correlates with akinesia of PD (13).

The neural mechanisms of LID, those that determine the clinical type of LID (i.e., choreic or dystonic) and those allowing the co-occurrence of Parkinsonism and biphasic dyskinesias, are still not fully understood (13-16).

The most accepted models of LID implicate pre- and postsynaptic changes at the cortico-striatal synapses and alterations in the activity of dopaminergic and non-dopaminergic (e.g., glutamatergic) neurotransmitter systems. The degeneration of dopaminergic neurons in the substantia nigra pars compacta (SNc) is associated with a series of changes in the nigro-striatal synapses such as a loss of tonic release of dopamine, diminished dopamine storage, and reuptake capacity [for review see Ref. (17)]. Positron emission imaging studies have demonstrated abnormally high levels of striatal dopamine 1-hour post-medication (18) and reduced dopamine transporter (DAT) levels (19) in dyskinetic patients. Brain concentrations of levodopa after peripheral administration were also found to be higher in dyskinetic rats than non-dyskinetic rats, though plasma levels were not different (20), confirming this association. The availability of extracellular dopamine after exogenous levodopa administration depends significantly on the serotoninergic neurons, which convert it to dopamine and provide vesicular storage $(21,22)$. These neurons, however, lack the DAT system and pre-synaptic dopamine D2 autoreceptors, which leads to unregulated release and reduced clearance of dopamine (23). Denervation-dependent D1 receptor super-sensitivity causing pronounced activation of the D1-bearing striatal neurons (15) and changes in the dendritic and synaptic morphology (24) are two other important post-synaptic determinants of LID in animal models. Enhanced D1 receptor pathway transmission in dyskinetic animal models can lead to hyperphosphorylation of key enzymes necessary for neural signaling in the direct pathway (25). For example, GluR1, a subunit of AMPA receptors, exhibits high phosphorylation levels of $\operatorname{Ser}_{831}$ and $\operatorname{Ser}_{845}$ in the membranes of medium spiny neurons (MSNs) after levodopa treatment in dyskinetic rats (26). Thus, advanced PD is a state characterized by the inability to maintain stable, physiological, synaptic and extra-synaptic levels of dopamine, which in turn favors aberrant pre- and post-synaptic plastic responses in the striatum.

Here, we review the theories of LID related to striatal and cortical maladaptive plasticity in PD in the light of (1) the recent studies on motor cortex plasticity in different stages of evolution of PD (27-31), (2) the current knowledge of the physiology and anatomy of basal ganglia circuitry, including the reciprocal subcortical connections between the basal ganglia and the cerebellum $(32,33)$, and (3) the recent report of the role of cerebellar sensory processing in the bidirectional modulation of primary motor cortex (M1) plasticity (34) and the disturbance of this function in patients with LID (30). We propose a model based on the plasticity changes in
PD that considers Parkinsonism, biphasic, and peak-dose dyskinesias as clinical manifestations of the abnormal interaction between M1 and the interlinked subcortical structures including the basal ganglia and cerebellum, during fluctuations in synaptic dopamine levels.

\section{BASAL GANGLIA CIRCUITRY}

\section{CORTICO-BASAL GANGLIO-THALAMO-CORTICAL LOOP}

Based on current understanding, the cortico-basal gangliacortical circuit functions as a complex, integrated network with multiple feed-back and feed-forward loops (35). The motor circuitry that projects from motor cortical areas (primary motor cortex, supplementary cortex, premotor cortex, and parts of the somatosensory dorsal parietal cortex) has a somatotopic, glutamatergic relay with the GABA-ergic MSNs in the dorsolateral portion of the post-commissural putamen and a small rim of the head of the caudate (36). The MSNs are connected to the output nuclei either indirectly, after relay in globus pallidus pars externa (GPe) and subthalamic nucleus (STN), or directly. The globus pallidus pars interna (GPi) and the substantia nigra pars reticulata $(\mathrm{SNr})$ are the output nuclei of the basal ganglia and project to the premotor neurons in the ventral tier of thalamic nuclei (i.e., ventro-anterior, VA and ventro-lateral, VL), the centromedian $(\mathrm{CM}) /$ parafascicular (PF) complex, the pedunculo-pontine nucleus, the superior colliculus, and the brain stem (37-39). The VA/VL thalamic nuclei project to the supplementary motor area (SMA) and, to a lesser extent, to M1 and premotor cortex (38). In addition to the afferent input from putaminal MSNs and GPe neurons to STN, a hyper-direct glutamatergic pathway relays input from M1, SMA proper and pre-SMA, and dorsal and ventral premotor cortices to the dorsal aspect of STN (40-42). These hyper-direct glutamatergic cortico-STN connections, along with the STN-GPe and GPe-GPi connections, constitute the corticoSTN-pallidal pathways that bypass the striatum. The STN also receives glutamatergic projections from the thalamic $\mathrm{PF}$ and $\mathrm{CM}$ nuclei $(43,44)$. There are direct projections from STN to the cortex $(45,46)$ and to the thalamus $(47)$. There are also dopaminergic projections from the SNc to STN $(48,49)$. Thus, dopamine can be seen to influence all glutamatergic synapses within the basal ganglia-thalamo-cortical circuit (Figure 1).

\section{RECIPROCAL BASAL GANGLIO-CEREBELLAR CIRCUITRY}

A major recent advance has been the identification of topographically organized, reciprocal links between basal ganglia and the cerebellum in non-human primates. Retrograde viral transporter studies in primates showed direct projection from the dentate nucleus, a major output of cerebellum, to the CM/PF complex intralaminar nuclei in the thalamus and subsequently to the dorsolateral putamen $(32,50)$. This bisynaptic path extends with a third synapse from putamen to GPe (32). It was recently shown in primates that the STN projects not only to the GPi, but also has topographically organized projections to lobule VII B and Crus II in the cerebellum via the pontine nuclei (51). The identification of bilateral subcortical communications between basal ganglia and cerebellum, besides their convergence to partially overlapping cortical areas (52-54), makes it imperative to examine the interaction between the abnormal basal ganglia activity and the 
cerebellar circuits in PD that could contribute to the development of Parkinsonism or LID.

\section{DOPAMINERGIC SIGNALING IN THE MOTOR CIRCUITS IN HEALTH \\ DOPAMINE AND BASAL GANGLIA}

Dopaminergic fibers from the $\mathrm{SNc}$ innervate the striatum and all structures in the basal ganglia, including the STN and GPi, as well as the prefrontal, motor, and sensory cortices (55). Striatal synaptic and extra-synaptic dopamine levels are maintained at a constant level (56), independent of SNc neuronal firing, due to the efficient dopamine reuptake by the DAT system in the striatum (57) and the auto-inhibition mediated by presynaptic dopamine D2 receptor stimulation (58). The cortex and thalamus send massive glutamatergic input to the GABA-ergic striatal MSNs $(59,60)$ and dopamine has a pre-synaptic modulatory effect on this excitation (61). Post-synaptically, dopamine also stabilizes the firing rate and excitability of striatal neurons, inhibiting D2-bearing neurons and facilitating D1-bearing striato-pallidal neurons (62). Dopamine also regulates plasticity of striatal neurons by modulating glutamate-mediated long-term potentiation (LTP), long-term depression (LTD), and depotentiation (which is a homeostatic mechanism of reversal of a potentiated synapse to its pre-potentiated state) at the cortico-striatal synapses (63). Striatal LTP and LTD are important for motor learning, while depotentiation is thought to be necessary for removing unnecessary motor information (64). The activation of D1 receptors is necessary for induction of both LTP and depotentiation, while the co-activation of D1 and D2 receptors is required for induction of LTD. Thus, the midbrain dopaminergic neurons [SNc-ventral tegmental area (VTA)], through their projections to multiple basal ganglia nodes that receive glutamatergic inputs, can influence the local neural transmission as well as the induction of plasticity at these nodes (Figure 1). Dopamine can also indirectly influence M1 plasticity by regulating the basal ganglia inputs reaching M1.

\section{DOPAMINE AND PRIMARY MOTOR CORTEX}

Neuroanatomical studies have confirmed the presence of direct dopaminergic innervations from the midbrain to $\mathrm{M} 1$ in rats (65, 66), monkeys (67), and human beings (68), as well as the presence of dopamine D1 and D2 receptors in M1 (69-72). A recent study, using the more specific DAT immunostaining method in mice, confirmed direct dopaminergic innervations of deep layers of M1 (73). D2 receptor agonists that increased the firing rate of pyramidal neurons proved the effect of dopamine on M1 neurons. This effect could be either due to a direct increase of pyramidal neuronal excitability or due to a reduction of inhibitory interneuronal activity (74). An important role of dopamine in $\mathrm{M} 1$ is to facilitate motor learning $(66,75)$ and motor memory encoding $(76)$. In rats, the impaired LTP and motor skills learning following dopaminergic deafferentation of $\mathrm{M} 1$ could be corrected by local administration of levodopa within M1 using osmotic mini-pumps (66). However, denervation of $\mathrm{SNc}$ resulted in a total loss of motor skills learning, far more severe than direct M1 denervation (77). Vitrac et al. (73) showed that D1 receptors can enhance the associability of the preand post-synaptic activity: by increasing the sensitivity and the time-window for LTP induction, they serve as "coincidence modulators" that can determine whether a synapse will undergo LTP in response to a set of activity patterns. Dopamine is also considered necessary for the stability of motor representations within M1, as local injection of D2 receptor blockers results in the collapse of motor representations and of motor cortex excitability (78). This may be because both D1 and D2 receptor-mediated mechanisms within M1 are necessary for the intracortical horizontal connections to form LTP (75).

In human beings, studies in which plastic changes in M1 were artificially induced with non-invasive stimulation techniques (e.g., transcranial direct current stimulation, tDCS, and transcranial magnetic stimulation, TMS) revealed that dopamine has a nonlinear dose-dependent effect on M1 plasticity (79-81), which is mediated through both D1 and D2 receptor subtypes (82). In healthy subjects, both low and excessive exogenous dopamine impair both facilitatory and inhibitory cortical plasticity (80, 83), while medium doses of oral levodopa have more stable effects and can even enhance performance in motor learning tasks (76).

\section{DOPAMINE AND CEREBELLUM}

Animal studies revealed that there is a small but well-defined dopaminergic system in the cerebellum, which expresses all types of dopamine receptors and whose properties are similar to the striatal dopaminergic system (84). It receives inputs from the $\mathrm{SNc}$ and VTA that terminate in the granule and Purkinje cell layers (85-88). This system is important for the optimal development and functioning of both the cerebellum and the basal ganglia. Loss of nigral neurons in neonatal 6-OHDA-treated rats affects postnatal cerebellar development (89) and the expression of $\mathrm{GABA}_{\mathrm{A}}$ receptor subtype (90). This highlights the dependency of cerebellar development on dopaminergic input, which could be direct or indirect through the basal ganglia. In addition, both the degeneration of Purkinje cells in a knock-out rat model (84) and kainic acid-induced degeneration of cerebellar cortex with preservation of deep cerebellar nuclei (91) led to up-regulation of D1 receptors and DAT in the striatum. This suggests that the cerebellar cortex, through the deep nuclei and the thalamic relay, down-regulates the striatal D1 receptors.

Besides the modulation of the striatal dopaminergic system, the cerebellum also regulates the cortical dopaminergic system, since electrical stimulation of dentate nucleus can induce dopamine release within the prefrontal cortex in mice (92). This might occur either through dentato-tegmental projections or through dentato-thalamo-cortical projections (93).

In healthy humans, fMRI studies have shown strong connectivity between SNc and cerebellum $(94,95)$. This connectivity between $\mathrm{SNc}$ and cerebellum is lost in PD but is restored by levodopa (96). Thus dopamine has both a direct and indirect influence on the cerebellum.

\section{DOPAMINERGIC SIGNALING IN PARIKINSONISIM AND LEVODOPA-INDUCED DYSKINESIA \\ STRIATAL SIGNALING}

According to the current models of basal ganglia in PD, dopamine depletion causes under-activation of GPe and disinhibition of STN 


\section{A Normal}

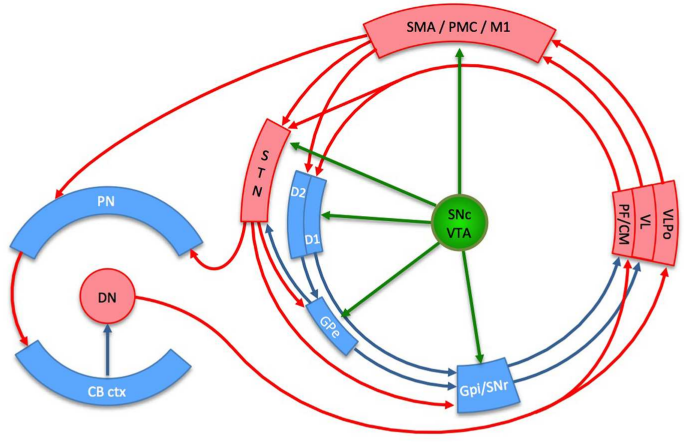

B Non-dyskinetic PD
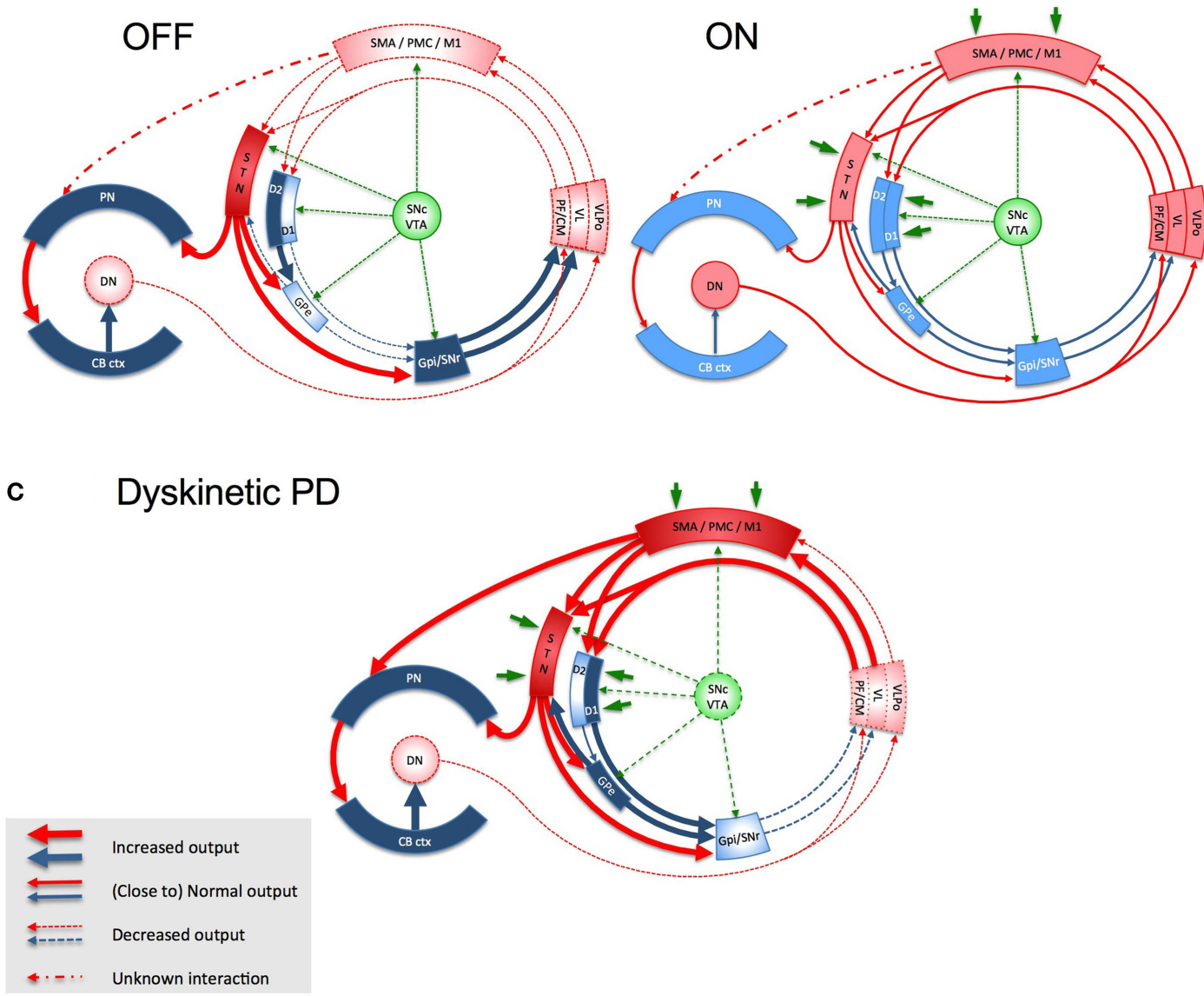

FIGURE 1 | Schematic representation of the basal gangliathalamo-cortical loop, the cerebello-thalamo-cortical loop and the interaction between the two in health (A), in non-dyskinetic Parkinson's disease, after levodopa withdrawal (OFF) and after regular dose of levodopa (ON) (B), and in advanced Parkinson's disease with levodopa-induced dyskinesia (C). Red arrows represent glutamatergic projections; blue arrows represent GABA-ergic projections; green arrows represent dopaminergic projections; dark green arrows in panel $B$ and $C$ represent the exogenous dopamine from levodopa. The shades of the blocks represent the activity of the respective network nodes. The STN is overactive because of cortical glutamatergic over activity during dyskinesias and from loss of GPe inhibition in OFF. The STN over activity locks cerebellar cortex in a persistent hyperactive state and interferes with its sensory processing function. The behavior of the cortico-ponto-cerebellar projections in non-dyskinetic PD in ON is not reported so far and is predicted by this model to be close to normal (CB ctx, cerebellar cortex; CM, centromedian thalamic nucleus; D1/D2, dopamine receptor types of the striatal medium spiny neurons (MSNs); DN, dentate nucleus; GPe, globus pallidus externus; GPi, globus pallidus internus; M1, primary motor cortex; PF, parafascicular nucleus; PMC, premotor cortex; PN, pontine nuclei; SMA, supplementary motor area; SNc, substantia nigra, pars compacta; $\mathrm{SNr}$, substantia nigra, pars reticulata; STN, subthalamic nucleus; VL, ventro-lateral thalamic nucleus; VLPo, ventro-latero-posterior thalamic nucleus, pars oralis; VTA, ventral tegmental area). 
in the indirect pathway (Figure 1B). STN over-activity in PD could not only be due to abnormalities of the indirect pathway, but also to the direct excitatory drive from the motor cortex and thalamus $(97,98)$. This could lead to excessive activation of GPi, a dysfunction favored also by the reduced input from D1 pathway. The net outcome would be enhanced GABA-ergic inhibition of thalamic projections to motor areas. It is now considered that not only firing rates but also firing patterns are important in maintaining normal signaling within the motor circuit. Intra-operative recordings in PD patients have demonstrated oscillations of local field potentials in the beta band in the STN that are synchronized with beta band oscillations in the cerebral cortex and GPi, indicating that excessive synchronization is a feature of the whole basal gangliacortical network. Dopaminergic drugs $(99,100)$ and STN DBS (101) can suppress the abnormal synchrony between basal ganglia and cortex. Moreover, suppression of beta band synchrony by these interventions positively correlates with improvement in bradykinesia and rigidity.

Levodopa treatment, however, does not restore basal ganglia activity to normal and LIDs are associated with reduced activity in the STN and GPi neurons. For example, peak oscillations at 4-10 Hz associated with dyskinesia were recorded only from the contralateral STN in patients with asymmetrical LID (102). Such abnormal oscillations in Parkinsonian and dyskinetic states could potentially propagate from the STN to the cerebellum in PD.

\section{STRIATAL PLASTICITY IN PARKINSONISM AND LID}

In animal studies, striatal LTP and LTD are both impaired if dopaminergic afferents to striatum are lesioned but can be restored by levodopa (103). In human beings, the direct evidence of dopaminergic influence on an extrastriatal site was demonstrated in SNr neuronal plasticity during DBS surgery; local field potential amplitude of SNr neurons showed no enhancement after high frequency stimulation of STN when tested without levodopa, but enhancement was evident following the administration of levodopa (104).

In the rat models of PD and LID, striatal LTP was impaired in both non-dyskinetic and dyskinetic rats and could be restored by levodopa in both groups (64). In contrast, the capacity to depotentiate LTP was preserved only in non-dyskinetic rats. In the rat model, both the presence of dyskinesias and the loss of depotentiation were linked to higher doses of levodopa (105). This shows that loss of depotentiation at the cortico-striatal synapses from levodopa exposure is a marker of LID in animal models.

\section{CORTICAL SIGNALING}

A significant loss of dopamine and noradrenaline occurs in the motor cortex of PD patients $(36,55,68)$. This postmortem finding was confirmed in vivo by PET of the motor cortex (106), motor cortical pathology was therefore proposed to underlie some of the symptoms of PD $(106,107)$. In line with this hypothesis, antiPD drugs can modulate the activity of motor cortex (108) and non-invasive stimulation of the motor cortex can help reduce symptoms of PD and LID by reestablishing the homeostasis of some circuits (109). However, the kinetics of cortical dopamine within M1 is yet to be explored in human beings and animal models of LID.

\section{MOTOR CORTEX PLASTICITY}

In human $\mathrm{PD}$, changes in motor cortex plasticity have been studied using transcranial magnetic stimulation (TMS), delivered alone as theta-burst (TBS) or as a paired associative stimulation (PAS), in which magnetic pulses delivered over M1 are classically associated with sensory pulses delivered on a peripheral nerve (Figure 2). The plastic effects of TBS depend on the stimulation pattern, which will act upon the intracortical synapses within M1. The sensorimotor plastic effects of PAS depend on the coincidence of pre- and post-synaptic neuronal activation within a specific time window (110-112). Using TBS in de novo PD, the LTP- and LTDlike plasticity of the intracortical circuits within M1was shown to be symmetrically and severely impaired even though the motor symptoms were unilateral (29). There was also no correlation of the plasticity loss with motor signs of $\mathrm{PD}$, indicating that that M1 changes were more likely the direct consequence of mesocortical denervation than the indirect consequence of striatal denervation, the latter being more correlated with Parkinsonian signs. It also indicates that changes in M1 plasticity occur at a lower level of dopaminergic denervation than the higher threshold of 60 $80 \%$ striatal dopaminergic denervation necessary for the motor signs to develop. Additionally, the local M1 plasticity in de novo patients did not show any short-duration response to a single dose of $100 \mathrm{mg}$ levodopa, while clinical deficits showed significant improvement. This indicated that normalization of plastic mechanisms within M1 needs sustained dopamine replenishment. It was subsequently demonstrated that the propensity of intracortical circuits in the motor cortex to express normal plastic responses was closely linked to the stability of clinical response to levodopa (28):

(1) Patients with stable clinical response to levodopa with no fluctuations in their clinical response to levodopa and without LID could express LTP and LTD even when tested without levodopa. This suggests a beneficial and persistent treatment effect of levodopa therapy on M1 plasticity when compared to the severe loss of plasticity in the untreated state.

(2) Patients with wearing-off motor fluctuation showed a persistent treatment effect of chronic levodopa treatment on LTP, but not on LTD. In these patients, exposure to an acute boost of dopamine, by administering their regular dose of levodopa, revealed a detrimental effect of dopamine on both LTP and LTD.

(3) Patients with both motor fluctuations and dyskinesias have no persistent treatment effect on either LTP or LTD. Acute boost of levodopa did not restore LTP or LTD. Interestingly, acute dopamine boost led to a paradoxical LTP in the motor cortex of these patients in response to an intervention that normally induces LTD in healthy subjects. The paradoxical facilitation was more in those with more severe disease and with higher clinical response to levodopa, suggesting that both are consequences of the acute dopamine replacement. Moreover, PD patients with LID are unable to depotentiate an already established LTP in M1after an acute dosing with even a small dose of levodopa (113). This finding is similar to changes in the striatum of dyskinetic animals (64), but in contrast to nondyskinetic patients in whom depotentiation was present after 


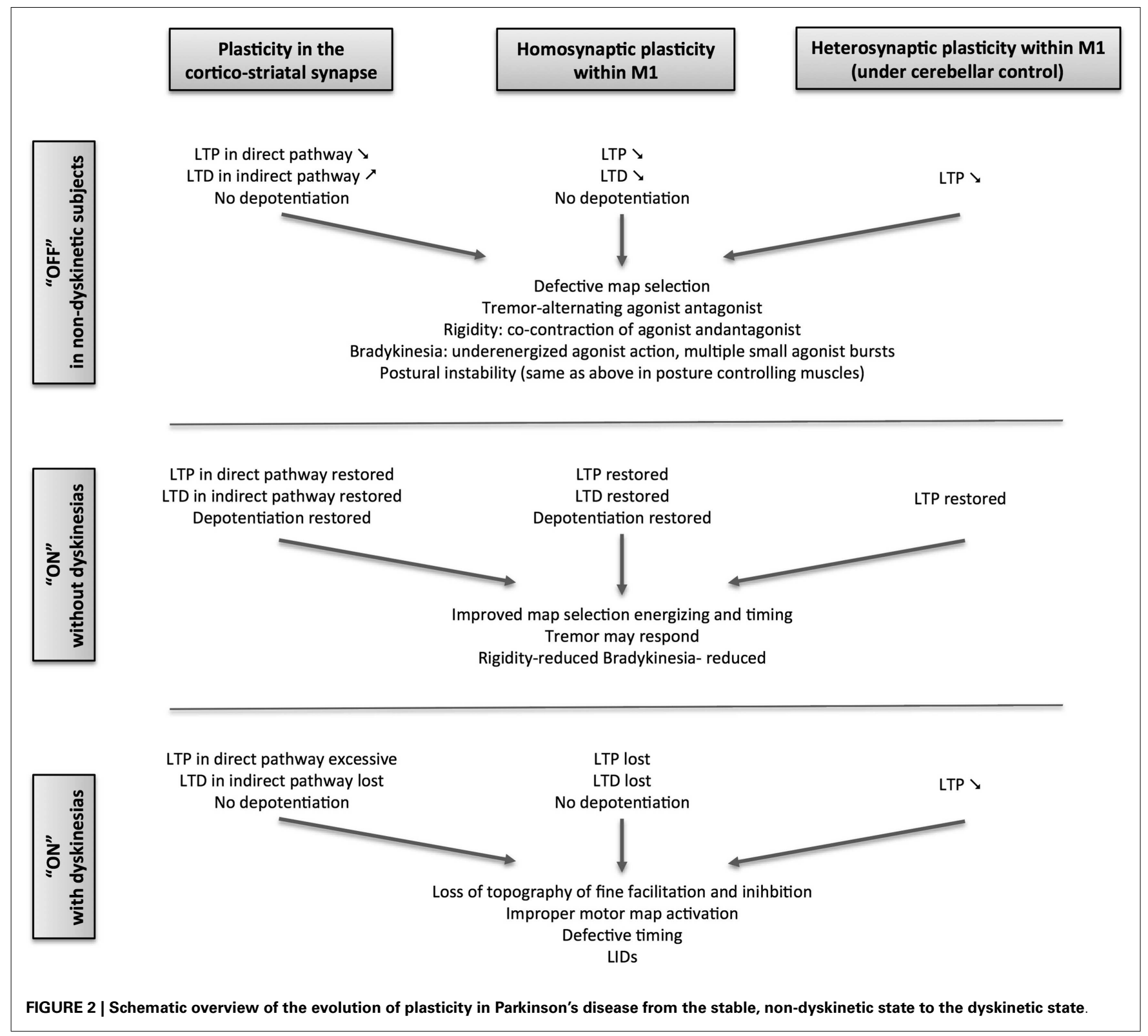

their regular dose of levodopa. PD patients with LID could express LTP in M1, but only when given half the regular dose of levodopa, reconfirming the negative effect of the regular dose on LTP. All these findings point to a severe dysregulation of intrinsic plastic mechanisms within M1 of patients with LID.

Additionally, studies using PAS have also revealed severe loss of sensorimotor, associative plasticity of $\mathrm{M} 1$ in the more affected hemisphere of de novo PD patients (31). Unlike the plastic response of the local intracortical circuits, the impairment in associative plasticity in the more affected hemisphere correlated with the severity of motor signs of PD, indicative of a dependence on striatal denervation underlying both. The short-duration response of associative plasticity to levodopa in de novo patients has not been studied so far. However, associative plasticity of M1can be restored by dopaminergic drugs only in chronically treated patients that are non-dyskinetic and not in dyskinetic ones (27).

Besides the plastic responses, intracortical inhibitory circuits are also altered in $\mathrm{M} 1$ of treated $\mathrm{PD}$ patients. $\mathrm{GABA}_{\mathrm{A}}$-mediated, short-interval intracortical inhibition is reduced in PD patients, both dyskinetic and non-dyskinetic, when compared to controls, and levodopa could not correct this (114). In the same study, long interval intracortical inhibition was weaker than in controls in both non-dyskinetic and dyskinetic patients tested without levodopa, but levodopa could weakly correct this in dyskinetic patients. The lack of positive effect of levodopa on intracortical inhibition in M1 and the negative effect of levodopa on short latency afferent inhibition (115) has also been suspected to play a role in LID. 


\section{CEREBELLAR LINK TO MOTOR CIRCUITS IN HEALTH, PARKINSONISM AND LID \\ CEREBELLAR PLASTICITY IN HEALTH}

Within the motor control loops, the cerebellum controls and co-ordinates complex movements and is important for adapting movements to changes in feed-back. It receives sensory and motor information from descending cortical pathways and from ascending peripheral pathways. It has also connections to the parietal, premotor, and frontal cortices. The two major excitatory afferents to cerebellum are the climbing fibers and mossy fiber - parallel fiber systems, information from both of which eventually converges on the Purkinje cells that represent the only efferent output from the cerebellar cortex. The exteroceptive and proprioceptive inputs from the spinal cord and the input from pontine nuclei convey information from brainstem nuclei via mossy fibers to the granule cells. The axons of granule cells form the parallel fibers network. Climbing fibers originate in the inferior olive and relay directly to the Purkinje cells. Plastic changes in the strength of synapses relaying from the climbing and parallel fibers to the Purkinje cells are important in motor learning. Plasticity of climbing fibers input bi-directionally adjusts the plasticity of parallel fibers-Purkinje cells synapses. This suggests a role of climbing fibers as an error detector, which signals the need for adjusting the gain of sensory inputs and/or motor output within the cerebellum. Any disturbance in cerebellar plasticity could interfere with this function and result in maladjusted information delivered to M1, leading to abnormal, movement sequences.

\section{CEREBELLAR PLASTICITY DYSFUNCTION IN PARKINSON'S DISEASE AND LID}

There are several lines of evidence suggesting that cerebellothalamo-cortical communication is abnormal in PD. In animal models of PD, the thalamic neurons that receive cerebellar output are underactive, just as those receiving basal ganglia afferents (116), indicative of a reduced dentato-thalamo-cortical excitatory output. In the MPTP mouse model, nigral degeneration is accompanied by loss of Purkinje cells in the cerebellum (117). In the untreated chronic MPTP monkey model of PD, nigral degeneration correlates with persistent hyperactivity in the cerebellum (118). Such a hyperactive state, secondary to striatal dopaminergic denervation, could prevent the efficient processing of the inputs from both parallel and climbing fibers, thus interfering with the plasticity mechanisms within the cerebellar cortex. One potential source of cerebellar hyperactivity could be the pathological hyperactivity in the glutamatergic projections from STN to cerebellum (Figures $\mathbf{1 B}, \mathbf{C}$ ). There is now increasing clinical, electrophysiological, and functional imaging evidence to invoke a cerebellar dysfunction in PD - for review see Ref. (119).

In the monkey model of $\mathrm{PD}$, the ventro-lateral posterior nucleus of the thalamus that receives cerebellar output shows oscillations at tremor frequency, while in human $\mathrm{PD}$, cerebellum has been linked to the postural tremor $(120,121)$. Also in PD patients, tremor-related abnormal oscillatory activity was recorded in the STN and GPi but not in the thalamic nuclei receiving basal ganglia input $(122,123)$. Considering the newly described anatomical connections between the basal ganglia and the cerebellum, it is conceivable that abnormal oscillations from a cerebellar circuit could propagate either to M1 and subsequently to STN via hyper-direct pathway, or from cerebellum to striatal MSNs projecting to GPe-STN via the indirect pathway. Defects in striatal dopamine release (124) and in cerebellar sensory processing function (125) were recently found in patients with primary focal dystonia. Abnormal signaling between basal ganglia and cerebellum in human PD could therefore potentially cause dystonic symptoms in untreated PD and during low plasma levels of dopamine as in biphasic dyskinesias.

Despite the classical view that LID might be generated exclusively by the disinhibition of cortical motor areas secondary to abnormal output from the basal ganglia in the striato-thalamocortical circuit (17), there is indirect evidence that the cerebellum may play a role in it.

In patients with $\mathrm{PD}$, the binding potential of sigma receptors in the cerebellum (as explored with PET) is highly increased with respect to healthy controls and correlates only with LID scores and not with severity scores of Parkinsonian signs (126). Sigma receptor stimulation influences Purkinje cell firing (127) and also plays a role in the modulation of the glutamatergic/NMDA neurotransmission in the dopaminergic systems (128). Successful stereotaxic pallidal surgery (either pallidotomy or deep-brain stimulation) can lower this exaggerated sigma receptor binding in the cerebellum in LID (126).

Further evidence of cerebellar involvement in LID comes from TMS studies. In patients with PD, with mild to moderate LID, repeated sessions of bilateral cerebellar inhibitory stimulation after regular doses of levodopa induce a sustained reduction of dyskinesia lasting at least 2 weeks $(30,129)$. Repeated cerebellar stimulation can also reduce the cerebellar cortical activity and enhance dentate nuclear activity in imaging studies in PD patients with dyskinesias (130). In such patients, a single session of inhibitory stimulation of the cerebellar cortex combined with levodopa can restore the sensorimotor plasticity tested by PAS, but not the local intracortical plasticity as tested with TBS (30). This effect of cerebellar stimulation would have improved M1 plasticity induced by both PAS and TBS, if cerebellar stimulation was modifying directly M1 excitability. The lack of effects of cerebellar stimulation on intracortical plasticity of M1 and on intrinsic cortical excitability parameters (as reflected by the motor thresholds or intracortical facilitation and inhibition) supports a primarily subcortical mechanism. Recent studies showed that cerebellar stimulation can modulate the M1 associative heterosynaptic plasticity in healthy subjects (131) through the modulation of peripheral sensory afferents (34), eventually scaling the amplitude and topographic specificity of the associative plastic response (34); excitation of the posterior cerebellar cortex led to loss of associative plastic response, while inhibition of the cerebellar cortex led to prolonged facilitatory response to PAS with loss of topographic specificity. These were observed for PAS but not for TBS, suggesting that the target of cerebellar modulation is mainly the afferent input to M1 rather than M1 in itself. Cerebellar cortical excitation (i.e., heightened output of the Purkinje cells) leads to the enhancement of the normal inhibition of the dentate nucleus, which would reduce the normal excitatory 
control of dentate nucleus on the afferent inflow to M1, probably at the thalamic or olivary nuclear level, thus blocking the sensorimotor-plasticity within M1. In contrast, cerebellar cortical inhibition (i.e., depressed output of the Purkinje cells) could lead to disinhibition of dentate nucleus, which would facilitate afferent input to M1 (34). This model is in keeping with the adaptive filtering role of the cerebellum on sensory afferents (132). Additionally, repeated sessions of inhibitory stimulation of the posterior cerebellar cortex can restore the levodopa-unresponsive, associative M1 plasticity in dyskinetic PD patients, concurrent with the reduction in LID severity (30). Several findings of this particular study suggested that the reduction in LID could be related to the improvement of responsiveness of M1 to PAS after cerebellar inhibition: (1) larger facilitation of M1 plasticity after a single session of cerebellar inhibitory stimulation in ON predicted greater anti-dyskinetic effect of repeated cerebellar stimulation in the same subjects; (2) the time course of LID improvement was similar to the time-course of the associative plasticity restoration after 10 consecutive sessions of cerebellar stimulation; and (3) patients with more severe LID before the TMS treatment showed larger responsiveness of M1 to cerebellar inhibition suggesting more involvement of the cerebellum in the pathophysiology of dyskinesias as the severity of LID increases. However, cerebellar stimulation did not worsen or enhance the Parkinsonian signs in OFF or beyond the effect of levodopa alone. Patient diaries revealed that the time spent in $\mathrm{ON}$ without troublesome dyskinesias, but not the durations of the OFF periods, was improved by cerebellar stimulation. These suggest that combined levodopa replacement therapy and cerebellar inhibition might be required to restore the balance between the two circuits and to concurrently improve Parkinsonian signs and reduce dyskinesias. Exogenously derived dopamine might act by increasing the excitability of M1 neurons (73) and normalizing basal ganglia signaling, whereas inhibition of the cerebellar cortex enhances the gain of the sensory afferent input and allow better sensorimotor integration (34). It remains speculative whether cerebellar hyperexcitation exists in de novo human $\mathrm{PD}$ as in de novo animal model of $\mathrm{PD}$ and if this cerebellar defect contributes to the genesis of specific manifestations like tremor or dyskinesias. If it were the case, then this metaplastic state of the cerebellar cortex could be reversed or delayed by early artificial inhibitory stimulation of the cerebellar cortex.

Earlier neuroimaging studies have found increased activity of motor and premotor areas in dyskinetic PD patients when compared to non-dyskinetic patients $(133,134)$. This led to the classical view that hyperactivity in cortical motor areas might be responsible for $\operatorname{LID}(17,135)$. However, inhibitory stimulation of SMA $(135,136)$ or of M1 (137) failed to provide sustained improvement of dyskinesias. The results obtained recently with cerebellar stimulation point to an alternative explanation, which reconciles with the observations in these older studies: as SMA, pre-motor cortex, and M1 are all targets of cerebellar output (54). An abnormal input from the cerebellum to SMA or M1 in dyskinetic patients might indeed trigger abnormal fMRI activations, but only as downstream, secondary, phenomena, thus making them unsuitable targets for a direct intervention for the treatment of LID.

\section{PROPOSED MODEL OF PARKINSONISM AND LEVODOPA-INDUCED DYSKINESIA BASED ON ABERRANT PLASTICITY}

This model is based on the view that a physiological level of dopaminergic stimulation is critical for maintaining normal plasticity at the glutamatergic terminals in the interconnected large motor network involving the basal ganglia, motor cortices, thalamus, and sensorimotor areas of the cerebellum. This model considers M1 only as the final target of this network and proposes LID as the product of a cascade of changes triggered by the altered dopaminergic signaling in this network. M1 neurons deprived of the ability to depotentiate activated synapses due to abnormally high synaptic dopamine levels during peak-dose, are rendered indiscriminately receptive to non-salient or even aberrant afferent inputs from the environment conveyed by other neural structures (spino-thalamic pathways via ventro-lateral thalamic nuclei, other cortical areas via direct cortico-cortical connections, etc.). This defect may be additionally amplified by the aberrant signals reaching M1 from the thalamic relays erratically modulated by the basal ganglia and cerebellum (Figure 1C). The result would be the inappropriate selection of motor programs and the generation of movements that are both unwanted and abnormal. The absence of effective inhibitory control within M1 and the paradoxical facilitation during attempted inhibition would make these movements resistant to voluntary suppression and even exacerbate them. Biphasic dyskinesia co-existing with Parkinsonism may reflect transitory oscillations in the synaptic dopamine levels during the rising and falling phases of release of exogenously derived dopamine. Such oscillations might allow concomitant manifestations of severe Parkinsonism and biphasic dyskinesias. This model needs further experimental validation. It also raises many questions that could be tested in future studies:

(1) Does DBS of the STN influence both STN-thalamo-cortical and STN-cerebellar transmission? Though the exact mechanisms by which DBS of the STN improves PD are not fully established, the fact that effective DBS of the STN improves cerebellar hyperactivity $(138,139)$ suggests that it may influence both the STN-GPi and the STN-cerebellar projections. Extracellular recordings in MPTP-intoxicated primates have shown that during DBS of the STN, significant change occurs in the pattern of neuronal activity in areas of the motor thalamus receiving both pallidal and cerebellar projections (140).

(2) The dose of administered levodopa has to be reduced after immediately after DBS of the STN to reduce dyskinesia. Does this indicate that DBS of the STN by itself cannot normalize the aberrant plasticity within M1 caused by dopamine surges, which would be necessary to alleviate dyskinesia? Preliminary data showing that sensorimotor cortex plasticity improves only after long-term synergistic combination of DBS with reduced doses of levodopa, but not after DBS alone (141). That long-term stimulation is required for restoring sensory afferent inhibition of M1(142) indicates that cerebellar control of sensory processing may also normalize only after chronic stimulation of STN. 
(3) Does selective DBS of the ventral GPi but not of the dorsal GPi or STN simultaneously inhibit the propagation of prodyskinetic signals through both cortico-striatal synapses and cerebello-striatal synapses (relayed through $\mathrm{CM} / \mathrm{PF}$ thalamic nuclei) on D1-bearing MSNs? It is already known that GPi has functional somatotopy (143) and that ventral GPi stimulation has anti-dyskinetic effects while dorsal GPi stimulation improves akinesia and induces dyskinesias (144). In primates, tightly connected functional circuits have been described between basal ganglia and the $\mathrm{CM} / \mathrm{PF}$, with a sensorimotor circuit linking the post-commissural putamen, the centrolateral part of the caudal GPi, and the medial two-thirds of the CM nucleus (145). The fact that CM/PF is a target for both pallidal and cerebellar inputs (39) might then explain why DBS of $\mathrm{CM} / \mathrm{PF}$ is useful for controlling tremor that is resistant to DBS of the STN and also LID that are only partially responsive to DBS of GPi. However, DBS alone of the $\mathrm{CM} / \mathrm{PF}$ does not change global UPDRS as strongly as DBS of the STN or GPi (146).

\section{REFERENCES}

1. Schrag A, Quinn N. Dyskinesias and motor fluctuations in Parkinson's disease. A community-based study. Brain (2000) 123(Pt 11):2297-305. doi:10.1093/ brain/123.11.2297

2. Fahn S, Oakes D, Shoulson I, Kieburtz K, Rudolph A, Lang A, et al. Levodopa and the progression of Parkinson's disease. New Engl J Med (2004) 351:2498-508. doi:10.1056/NEJMoa033447

3. Khan N, Graham E, Critchley P, Schrag A, Wood N, Lees A, et al. Parkin disease: a phenotypic study of a large case series. Brain (2003) 126:1279-92. doi:10.1093/brain/awg142

4. Papapetropoulos S, Argyriou A, Ellul J, Chroni E. Comparison of motor fluctuations and L-dopa-induced dyskinesias in patients with familial and sporadic Parkinson's disease. Eur J Neurol (2004) 11:115-9. doi:10.1046/j.1351-5101. 2003.00727.x

5. Nishioka K, Kefi M, Jasinska-Myga B, Wider C, Vilariño-Güell C, Ross O, et al. A comparative study of LRRK2, PINK1 and genetically undefined familial Parkinson's disease. J Neurol Neurosurg Psych (2010) 81:391-5. doi:10.1136/ jnnp.2009.185231

6. de Lau LM, Verbaan D, Marinus J, Heutink P, van Hilten JJ. Catechol-Omethyltransferase Val158Met and the risk of dyskinesias in Parkinson's disease. Mov Dis (2012) 27:132-5. doi:10.1002/mds.23805

7. Oliveri RL, Annesi G, Zappia M, Civitelli D, Montesanti R, Branca D, et al. Dopamine D2 receptor gene polymorphism and the risk of levodopa-induced dyskinesias in PD. Neurology (1999) 53:1425-30. doi:10.1212/WNL.53.7.1425

8. Kaiser R, Hofer A, Grapengiesser A, Gasser T, Kupsch A, Roots I, et al. L-dopainduced adverse effects in PD and dopamine transporter gene polymorphism. Neurology (2003) 60:1750-5. doi:10.1212/01.WNL.0000068009.32067.A1

9. Kaplan N, Vituri A, Korczyn A, Cohen O, Inzelberg R, Yahalom G, et al. Sequence variants in SLC6A3, DRD2, and BDNF genes and time to levodopainduced dyskinesias in Parkinson's disease. J Mol Neurosci (2014) 53:183-8. doi:10.1007/s12031-014-0276-9

10. Foltynie T, Cheeran B, Williams-Gray C, Edwards M, Schneider S, Weinberger $\mathrm{D}$, et al. BDNF val66met influences time to onset of levodopa induced dyskinesia in Parkinson's disease. J Neurol Neurosurg Psychiatry (2009) 80:141-4. doi:10.1136/jnnp.2008.154294

11. Muenter MD, Tyce GM. L-dopa therapy of Parkinson's disease: plasma L-dopa concentration, therapeutic response, and side effects. Mayo Clin Proc (1971) 46:231-9.

12. Muenter M, Sharpless N, Tyce G, Darley F. Patterns of dystonia ("I-D-I" and "D-I-D-") in response to L-dopa therapy for Parkinson's disease. Mayo Clin Proc (1977) 52:163-74.

13. Fabbrini G, Brotchie J, Grandas F, Nomoto M, Goetz C. Levodopa-induced dyskinesias. Mov Disord (2007) 22:1379-89. doi:10.1002/mds.21475
14. Olanow CW, Obeso JA, Stocchi F. Continuous dopamine-receptor treatment of Parkinson's disease: scientific rationale and clinical implications. Lancet Neurol (2006) 5:677-87. doi:10.1016/S1474-4422(06)70521-X

15. Cenci M, Ohlin K, Rylander D. Plastic effects of L-DOPA treatment in the basal ganglia and their relevance to the development of dyskinesia. Parkinsonism Relat Disord (2009) 15(Suppl 3):S59-63. doi:10.1016/S1353-8020(09) 70782-5

16. Calabresi P, Filippo M, Ghiglieri V, Tambasco N, Picconi B. Levodopa-induced dyskinesias in patients with Parkinson's disease: filling the bench-to-bedside gap. Lancet Neurol (2010) 9:1106-17. doi:10.1016/S1474-4422(10)70218-0

17. Bezard E, Brotchie JM, Gross CE. Pathophysiology of levodopa-induced dyskinesia: potential for new therapies. Nat Rev Neurosci (2001) 2:577-88. doi: $10.1038 / 35086062$

18. de la Fuente-Fernández R, Sossi V, Huang Z, Furtado S, Lu J-QQ, Calne DB, et al. Levodopa-induced changes in synaptic dopamine levels increase with progression of Parkinson's disease: implications for dyskinesias. Brain (2004) 127:2747-54. doi:10.1093/brain/awh290

19. Troiano AR, de la Fuente-Fernandez R, Sossi V, Schulzer M, Mak E, Ruth TJ, et al. PET demonstrates reduced dopamine transporter expression in PD with dyskinesias. Neurology (2009) 72:1211-6. doi:10.1212/01.wnl.0000338631. 73211.56

20. Carta M, Lindgren HS, Lundblad M, Stancampiano R, Fadda F, Cenci MA. Role of striatal L-DOPA in the production of dyskinesia in 6-hydroxydopamine lesioned rats. J Neurochem (2006) 96:1718-27. doi:10.1111/j.1471-4159.2006. 03696.x

21. Carta M, Carlsson T, Kirik D, Björklund A. Dopamine released from 5-HT terminals is the cause of L-DOPA-induced dyskinesia in Parkinsonian rats. Brain (2007) 130:1819-33. doi:10.1093/brain/awm082

22. Tanaka H, Kannari K, Maeda T, Tomiyama M, Suda T, Matsunaga M. Role of serotonergic neurons in L-DOPA-derived extracellular dopamine in the striatum of 6-OHDA-lesioned rats. Neuroreport (1999) 10:631-4. doi:10.1097/ 00001756-199902250-00034

23. Lindgren H, Andersson D, Lagerkvist S, Nissbrandt H, Cenci M. L-DOPAinduced dopamine efflux in the striatum and the substantia nigra in a rat mode of Parkinson's disease: temporal and quantitative relationship to the expression of dyskinesia. J Neurochem (2010) 112:1465-76. doi:10.1111/j.1471-4159. 2009.06556.x

24. Ingham CA, Hood SH, van Maldegem B, Weenink A, Arbuthnott GW. Morphological changes in the rat neostriatum after unilateral 6-hydroxydopamine injections into the nigrostriatal pathway. Exp Brain Res (1993) 93:17-27. doi:10.1007/BF00227776

25. Santini E, Valjent E, Usiello A, Carta M, Borgkvist A, Girault J-A, et al. Critical involvement of cAMP/DARPP-32 and extracellular signal-regulated protein kinase signaling in L-DOPA-induced dyskinesia. J Neurosci (2007) 27:6995-7005. doi:10.1523/JNEUROSCI.0852-07.2007

26. Yang X, Chen Y, Hong X, Wu N, Song L, Yuan W, et al. Levodopa/benserazide microspheres reduced levodopa-induced dyskinesia by downregulating phosphorylated GluR1 expression in 6-OHDA-lesioned rats. Drug Des Devel Ther (2012) 6:341-7. doi:10.2147/DDDT.S38008

27. Morgante F, Espay A, Gunraj C, Lang A, Chen R. Motor cortex plasticity in Parkinson's disease and levodopa-induced dyskinesias. Brain (2006) 129:1059-69. doi:10.1093/brain/awl031

28. Kishore A, Popa T, Velayudhan B, Joseph T, Balachandran A, Meunier S. Acute dopamine boost has a negative effect on plasticity of the primary motor cortex in advanced Parkinson's disease. Brain (2012) 135:2074-88. doi:10.1093/brain/aws124

29. Kishore A, Joseph T, Velayudhan B, Popa T, Meunier S. Early, severe and bilateral loss of LTP and LTD-like plasticity in motor cortex (M1) in de novo Parkinson's disease. Clin Neurophysiol (2012) 123:822-8. doi:10.1016/j.clinph.2011.06.034

30. Kishore A, Popa T, Balachandran A, Chandran S, Pradeep S, Backer F, et al. Cerebellar sensory processing alterations impact motor cortical plasticity in Parkinson's disease: clues from dyskinetic patients. Cereb Cortex (2013) 24(8):2055-67. doi:10.1093/cercor/bht058

31. Kojovic M, Bologna M, Kassavetis P, Murase N. Functional reorganization of sensorimotor cortex in early Parkinson disease. Neurology (2012) 78:1441-8. doi:10.1212/WNL.0b013e318253d5dd

32. Hoshi E, Tremblay L, Féger J, Carras P, Strick P. The cerebellum communicates with the basal ganglia. Nat Neurosci (2005) 8:1491-3. doi:10.1038/nn 1544 
33. Bostan AC, Strick PL. The cerebellum and basal ganglia are interconnected. Neuropsychol Rev (2010) 20:261-70. doi:10.1007/s11065-010-9143-9

34. Popa T, Velayudhan B, Hubsch C, Pradeep S, Roze E, Vidailhet M, et al. Cerebellar processing of sensory inputs primes motor cortex plasticity. Cereb Cortex (2013) 23:305-14. doi:10.1093/cercor/bhs016

35. DeLong M, Wichmann T. Update on models of basal ganglia function and dysfunction. Parkinsonism Relat Disord (2009) 15(Suppl 3):S237-40. doi:10.1016/S1353-8020(09)70822-3

36. Smith Y, Kieval J. Anatomy of the dopamine system in the basal ganglia. Trends Neurosci (2000) 23:S28-33. doi:10.1016/S1471-1931(00)00023-9

37. Parent M, Parent A. The pallidofugal motor fiber system in primates. Parkinsonism Relat Disord (2004) 10:203-11. doi:10.1016/j.parkreldis.2004.02.007

38. Nakano K. Neural circuits and topographic organization of the basal ganglia and related regions. Brain Dev (2000) 22(Suppl 1):S5-16. doi:10.1016/S03877604(00)00139-X

39. Percheron G, François C, Talbi B, Yelnik J, Fénelon G. The primate motor thalamus. Brain Res Rev (1996) 22:93-181. doi:10.1016/0165-0173(96)00003-3

40. Nambu A, Takada M, Inase M, Tokuno H. Dual somatotopical representations in the primate subthalamic nucleus: evidence for ordered but reversed bodymap transformations from the primary motor cortex and the supplementary motor area. J Neuroscience (1996) 16:2671-83.

41. Nambu A, Tokuno H, Inase M, Takada M. Corticosubthalamic input zones from forelimb representations of the dorsal and ventral divisions of the premotor cortex in the macaque monkey: comparison with the input zones from the primary motor cortex and the supplementary motor area. Neurosci Lett (1997) 239:13-6. doi:10.1016/S0304-3940(97)00877-X

42. Nambu A, Tokuno H, Takada M. Functional significance of the corticosubthalamo-pallidal "hyperdirect" pathway. Neurosci Res (2002) 43:111-7. doi:10.1016/S0168-0102(02)00027-5

43. Sadikot A, Parent A, François C. Efferent connections of the centromedian and parafascicular thalamic nuclei in the squirrel monkey: a PHA-L study of subcortical projections. J Comp Neurol (1992) 315:137-59. doi:10.1002/cne. 903150203

44. Lanciego JL, López IP, Rico AJ, Aymerich MS, Pérez-Manso M, Conte L, et al. The search for a role of the caudal intralaminar nuclei in the pathophysiology of Parkinson's disease. Brain Res Bull (2009) 78:55-9. doi:10.1016/j.brainresbull. 2008.08.008

45. Jackson A, Crossman AR. Subthalamic nucleus efferent projection to the cerebral cortex. Neuroscience (1981) 6:2367-77. doi:10.1016/0306-4522(81) 90023-3

46. Degos B, Deniau J-MM, Le Cam J, Mailly P, Maurice N. Evidence for a direct subthalamo-cortical loop circuit in the rat. Eur J Neurosci (2008) 27:2599-610. doi:10.1111/j.1460-9568.2008.06229.x

47. Rico AJ, Barroso-Chinea P, Conte-Perales L, Roda E, Gómez-Bautista V, Gendive $\mathrm{M}$, et al. A direct projection from the subthalamic nucleus to the ventral thalamus in monkeys. Neurobiol Dis (2010) 39:381-92. doi:10.1016/j.nbd. 2010.05.004

48. Lavoie B, Smith Y, Parent A. Dopaminergic innervation of the basal ganglia in the squirrel monkey as revealed by tyrosine hydroxylase immunohistochemistry. J Comp Neurol (1989) 289:36-52. doi:10.1002/cne.902890104

49. François C, Savy C, Jan C, Tande D, Hirsch EC, Yelnik J. Dopaminergic innervation of the subthalamic nucleus in the normal state, in MPTP-treated monkeys, and in Parkinson's disease patients. J Comp Neurol (2000) 425:121-9. doi:10.1002/1096-9861(20000911)425:1<121::AID-CNE10>3.0.CO;2-G

50. Ichinohe N, Mori F, Shoumura K. A di-synaptic projection from the lateral cerebellar nucleus to the laterodorsal part of the striatum via the central lateral nucleus of the thalamus in the rat. Brain Res (2000) 880:191-7. doi:10.1016/S0006-8993(00)02744-X

51. Bostan A, Dum R, Strick P. The basal ganglia communicate with the cerebellum Proc Natl Acad Sci U S A (2010) 107:8452-6. doi:10.1073/pnas.1000496107

52. Hoover JE, Strick PL. The organization of cerebellar and basal ganglia outputs to primary motor cortex as revealed by retrograde transneuronal transport of herpes simplex virus type 1. J Neurosci (1999) 19:1446-63.

53. Clower D, Dum R, Strick P. Basal ganglia and cerebellar inputs to “AIP.”. Cereb Cortex (2005) 15:913-20. doi:10.1093/cercor/bhh190

54. Akkal D, Dum R, Strick P. Supplementary motor area and presupplementary motor area: targets of basal ganglia and cerebellar output. J Neurosci (2007) 27:10659-73. doi:10.1523/JNEUROSCI.3134-07.2007
55. Prensa L, Cossette M, Parent A. Dopaminergic innervation of human basal ganglia. J Chem Neuroanat (2000) 20:207-13. doi:10.1016/S0891-0618(00) 00099-5

56. Venton B, Zhang H, Garris P, Phillips P, Sulzer D, Wightman R. Real-time decoding of dopamine concentration changes in the caudate-putamen during tonic and phasic firing. J Neurochem (2003) 87:1284-95. doi:10.1046/j.14714159.2003.02109.x

57. Sesack S, Carr D, Omelchenko N, Pinto A. Anatomical substrates for glutamatedopamine interactions: evidence for specificity of connections and extrasynaptic actions. Ann N Y Acad Sci (2003) 1003:36-52. doi:10.1196/annals.1300.066

58. Benoit-Marand M, Borrelli E, Gonon F. Inhibition of dopamine release via presynaptic D2 receptors: time course and functional characteristics in vivo. $J$ Neurosci (2001) 21:9134-41.

59. Doucet G, Descarries L, Garcia S. Quantification of the dopamine innervation in adult rat neostriatum. Neuroscience (1986) 19:427-45. doi:10.1016/03064522(86)90272-1

60. Kita H. GABAergic circuits of the striatum. Progr Brain Res (1993) 99:51-72. doi:10.1016/S0079-6123(08)61338-2

61. West A, Grace A. Opposite influences of endogenous dopamine D1 and D2 receptor activation on activity states and electrophysiological properties of striatal neurons: studies combining in vivo intracellular recordings and reverse microdialysis. J Neurosci (2002) 22:294-304.

62. Obeso J, Rodriguez-Oroz M, Rodriguez M, DeLong M, Olanow C. Pathophysiology of levodopa-induced dyskinesias in Parkinson's disease: problems with the current model. Ann Neurol (2000) 47:S22-32; discussion S32-4.

63. Calabresi P, Gubellini P, Centonze D, Picconi B, Bernardi G, Chergui K, et al. Dopamine and cAMP-regulated phosphoprotein $32 \mathrm{kDa}$ controls both striatal long-term depression and long-term potentiation, opposing forms of synaptic plasticity. J Neurosci (2000) 20:8443-51.

64. Picconi B, Centonze D, Håkansson K, Bernardi G, Greengard P, Fisone G, et al. Loss of bidirectional striatal synaptic plasticity in L-DOPA-induced dyskinesia. Nat Neurosci (2003) 6:501-6. doi:10.1038/nn1040

65. Descarries L, Lemay B, Doucet G, Berger B. Regional and laminar density of the dopamine innervation in adult rat cerebral cortex. Neuroscience (1987) 21:807-24. doi:10.1016/0306-4522(87)90038-8

66. Hosp J, Pekanovic A, Rioult-Pedotti M, Luft A. Dopaminergic projections from midbrain to primary motor cortex mediate motor skill learning. J Neurosci (2011) 31:2481-7. doi:10.1523/JNEUROSCI.5411-10.2011

67. Raghanti M, Stimpson C, Marcinkiewicz J, Erwin J, Hof P, Sherwood C. Cortical dopaminergic innervation among humans, chimpanzees, and macaque monkeys: a comparative study. Neuroscience (2008) 155:203-20. doi:10.1016/ j.neuroscience.2008.05.008

68. Gaspar P, Duyckaerts C, Alvarez C, Javoy-Agid F, Berger B. Alterations of dopaminergic and noradrenergic innervations in motor cortex in Parkinson's disease. Ann Neurol (1991) 30:365-74. doi:10.1002/ana.410300308

69. Camps M, Kelly PH, Palacios JM. Autoradiographic localization of dopamine D 1 and D 2 receptors in the brain of several mammalian species. J Neural Transm Gen Sect (1990) 80:105-27. doi:10.1007/BF01257077

70. Mansour A, Meador-Woodruff J, Bunzow J, Civelli O, Akil H, Watson S. Localization of dopamine D2 receptor mRNA and D1 and D2 receptor binding in the rat brain and pituitary: an in situ hybridization-receptor autoradiographic analysis. J Neurosci (1990) 10:2587-600.

71. Gaspar P, Bloch B, Le Moine C. D1 and D2 receptor gene expression in the rat frontal cortex: cellular localization in different classes of efferent neurons. Eur J Neurosci (1995) 7:1050-63. doi:10.1111/j.1460-9568.1995.tb01092.x

72. Santana N, Mengod G, Artigas F. Quantitative analysis of the expression of dopamine D1 and D2 receptors in pyramidal and GABAergic neurons of the rat prefrontal cortex. Cereb Cortex (2009) 19:849-60. doi:10.1093/cercor/ bhn 134

73. Vitrac C, Péron S, Frappé I, Fernagut P-OO, Jaber M, Gaillard A, et al. Dopamine control of pyramidal neuron activity in the primary motor cortex via D2 receptors. Front Neural Circuits (2014) 8:13. doi:10.3389/fncir.2014 00013

74. Xu T-XX, Yao W-DD. D1 and D2 dopamine receptors in separate circuits cooperate to drive associative long-term potentiation in the prefrontal cortex. Proc Natl Acad Sci U S A (2010) 107:16366-71. doi:10.1073/pnas.1004108107

75. Molina-Luna K, Pekanovic A, Röhrich S, Hertler B, Schubring-Giese M, RioultPedotti MS, et al. Dopamine in motor cortex is necessary for skill learning 
and synaptic plasticity. PLoS One (2009) 4:e7082. doi:10.1371/journal.pone. 0007082

76. Flöel A, Breitenstein C, Hummel F, Celnik P, Gingert C, Sawaki L, et al. Dopaminergic influences on formation of a motor memory. Ann Neurol (2005) 58:121-30. doi:10.1002/ana.20536

77. Hosp JA, Luft AR. Dopaminergic meso-cortical projections to $\mathrm{ml}$ : role in motor learning and motor cortex plasticity. Front Neurol (2013) 4:145. doi:10.3389/fneur.2013.00145

78. Hosp J, Molina-Luna K, Hertler B, Atiemo C, Luft A. Dopaminergic modulation of motor maps in rat motor cortex: an in vivo study. Neuroscience (2009) 159:692-700. doi:10.1016/j.neuroscience.2008.12.056

79. Fresnoza S, Paulus W, Nitsche MA, Kuo M-FF. Nonlinear dose-dependent impact of D1 receptor activation on motor cortex plasticity in humans. J Neurosci (2014) 34:2744-53. doi:10.1523/JNEUROSCI.3655-13.2014

80. Monte-Silva K, Liebetanz D, Grundey J, Paulus W, Nitsche MA. Dosagedependent non-linear effect of L-dopa on human motor cortex plasticity. $J$ Physiol (2010) 588:3415-24. doi:10.1113/jphysiol.2010.190181

81. Monte-Silva K, Kuo M-FF, Thirugnanasambandam N, Liebetanz D, Paulus W, Nitsche MA. Dose-dependent inverted U-shaped effect of dopamine (D2like) receptor activation on focal and nonfocal plasticity in humans. J Neurosci (2009) 29:6124-31. doi:10.1523/JNEUROSCI.0728-09.2009

82. Nitsche MA, Kuo M-FF, Grosch J, Bergner C, Monte-Silva K, Paulus W. D1receptor impact on neuroplasticity in humans. J Neurosci (2009) 29:2648-53. doi:10.1523/JNEUROSCI.5366-08.2009

83. Thirugnanasambandam N, Grundey J, Paulus W, Nitsche MA. Dose-dependent nonlinear effect of L-DOPA on paired associative stimulation-induced neuroplasticity in humans. J Neurosci (2011) 31:5294-9. doi:10.1523/JNEUROSCI. 6258-10.2011

84. Giompres P, Delis F. Dopamine transporters in the cerebellum of mutant mice. Cerebellum (2005) 4:105-11. doi:10.1080/14734220510007851

85. Panagopoulos N, Papadopoulos G, Matsokis N. Dopaminergic innervation and binding in the rat cerebellum. Neursci Lett (1991) 130(2):208-12. doi:10.1016/ 0304-3940(91)90398-D

86. Panagopoulos N, Matsokis N, Valcana T. Cerebellar and striatal dopamine receptors: effects of reeler and weaver murine mutations. J Neurosci Res (1993) 35(5):499-506. doi:10.1002/jnr.490350506

87. Ikai Y, Takada M, Shinonaga Y, Mizuno N. Dopaminergic and nondopaminergic neurons in the ventral tegmental area of the rat project, respectively, to the cerebellar cortex and deep cerebellar nuclei. Neuroscience (1992) 51:719-28. doi:10.1016/0306-4522(92)90310-X

88. Melchitzky D, Lewis D. Tyrosine hydroxylase-and dopamine transporterimmunoreactive axons in the primate cerebellum. Neuropsychopharmacology (2000) 22:466-72. doi:10.1016/S0893-133X(99)00139-6

89. Robain O, Lanfumey L, Adrien J, Farkas E. Developmental changes in the cerebellar cortex after locus ceruleus lesion with 6-hydroxydopamine in the rat. Exp Neurol (1985) 88:150-64. doi:10.1016/0014-4886(85)90120-7

90. Podkletnova I, Rothstein J, Helen P, Alho H. Microglial response to the neurotoxicity of 6-hydroxydopamine in neonatal rat cerebellum. Int J Dev Neurosci (2001) 19:47-52. doi:10.1016/S0736-5748(00)00069-1

91. Delis F, Mitsacos A, Giompres P. Lesion of the cerebellar paravermis increases dopamine D1 receptor levels in the contralateral striatum. J Chem Neuroanat (2013) 47:35-41. doi:10.1016/j.jchemneu.2012.10.004

92. Mittleman G, Goldowitz D, Heck D, Blaha C. Cerebellar modulation of frontal cortex dopamine efflux in mice: relevance to autism and schizophrenia. Synapse (2008) 62:544-50. doi:10.1002/syn.20525

93. Rogers T, Dickson P, Heck D, Goldowitz D, Mittleman G, Blaha C. Connecting the dots of the cerebro-cerebellar role in cognitive function: neuronal pathways for cerebellar modulation of dopamine release in the prefrontal cortex. Synapse (2011) 65:1204-12. doi:10.1002/syn.20960

94. Hacker C, Perlmutter J, Criswell S, Ances B, Snyder A. Resting state functional connectivity of the striatum in Parkinson's disease. Brain (2012) 135:3699-711. doi:10.1093/brain/aws281

95. Kwon HG, Jang SH. Differences in neural connectivity between the substantia nigra and ventral tegmental area in the human brain. Front Hum Neurosci (2014) 8:41. doi:10.3389/fnhum.2014.00041

96. Jech R, Mueller K, Schroeter ML, Ružicka E. Levodopa increases functional connectivity in the cerebellum and brainstem in Parkinson's disease. Brain (2013) 136:e234. doi:10.1093/brain/awt015
97. Blandini F, Garcia-Osuna M, Greenamyre JT. Subthalamic ablation reverses changes in basal ganglia oxidative metabolism and motor response to apomorphine induced by nigrostriatal lesion in rats. Eur J Neurosci (1997) 9:1407-13. doi:10.1111/j.1460-9568.1997.tb01495.x

98. Breit S, Bouali-Benazzouz R, Popa RC, Gasser T, Benabid AL, Benazzouz A. Effects of 6-hydroxydopamine-induced severe or partial lesion of the nigrostriatal pathway on the neuronal activity of pallido-subthalamic network in the rat. Exp Neurol (2007) 205:36-47. doi:10.1016/j.expneurol.2006.12.016

99. Silberstein P, Oliviero A, Lazzaro V, Insola A, Mazzone P, Brown P. Oscillatory pallidal local field potential activity inversely correlates with limb dyskinesias in Parkinson's disease. Exp Neurol (2005) 194:523-9. doi:10.1016/j.expneurol. 2005.03.014

100. Kühn A, Kupsch A, Schneider G-H, Brown P. Reduction in subthalamic 8-35 Hz oscillatory activity correlates with clinical improvement in Parkinson's disease. Eur J Neurosci (2006) 23:1956-60. doi:10.1111/j.1460-9568.2006. 04717.x

101. Brown P, Oliviero A, Mazzone P, Insola A, Tonali P, Lazzaro V. Dopamine dependency of oscillations between subthalamic nucleus and pallidum in Parkinson's disease. J Neurosci (2001) 21:1033-8.

102. Alonso-Frech F, Zamarbide I, Alegre M, Rodríguez-Oroz MC, Guridi J, Manrique $\mathrm{M}$, et al. Slow oscillatory activity and levodopa-induced dyskinesias in Parkinson's disease. Brain (2006) 129:1748-57. doi:10.1093/brain/awl103

103. Centonze D, Gubellini P, Picconi B, Calabresi P, Giacomini P, Bernardi G. Unilateral dopamine denervation blocks corticostriatal LTP. J Neurophysiol (1999) 82:3575-9.

104. Prescott IA, Dostrovsky JO, Moro E, Hodaie M, Lozano AM, Hutchison WD. Levodopa enhances synaptic plasticity in the substantia nigra pars reticulata of Parkinson's disease patients. Brain (2009) 132:309-18. doi:10.1093/brain/ awn322

105. Picconi B, Paillé V, Ghiglieri V, Bagetta V, Barone I, Lindgren H, et al. L-DOPA dosage is critically involved in dyskinesia via loss of synaptic depotentiation. Neurobiol Dis (2008) 29:327-35. doi:10.1016/j.nbd.2007.10.001

106. Moore R, Whone A, Brooks D. Extrastriatal monoamine neuron function in Parkinson's disease: an 18F-dopa PET study. Neurobiol Dis (2008) 29:381-90. doi:10.1016/j.nbd.2007.09.004

107. Luft A, Schwarz S. Dopaminergic signals in primary motor cortex. Int J Dev Neurosci (2009) 27:415-21. doi:10.1016/j.ijdevneu.2009.05.004

108. Lefaucheur J-P. Motor cortex dysfunction revealed by cortical excitability studies in Parkinson's disease: influence of anti-Parkinsonian treatment and cortica stimulation. Clin Neurophysiol (2005) 116:244-53. doi:10.1016/j.clinph.2004. 11.017

109. Elahi B, Elahi B, Chen R. Effect of transcranial magnetic stimulation on Parkinson motor function - systematic review of controlled clinical trials. Mov Disord (2009) 24:357-63. doi:10.1002/mds.22364

110. Stefan K, Kunesch E, Benecke R, Cohen L, Classen J. Mechanisms of enhancement of human motor cortex excitability induced by interventional paired associative stimulation. J Physiol (2002) 543:699-708. doi:10.1113/jphysiol. 2002.023317

111. Stefan K, Kunesch E, Cohen L, Benecke R, Classen J. Induction of plasticity in the human motor cortex by paired associative stimulation. Brain (2000) $123(\mathrm{Pt}$ 3):572-84. doi:10.1093/brain/123.3.572

112. Wolters A, Sandbrink F, Schlottmann A, Kunesch E, Stefan K, Cohen L, et al. A temporally asymmetric Hebbian rule governing plasticity in the human motor cortex. J Neurophysiol (2003) 89:2339-45. doi:10.1152/jn.00900.2002

113. Huang Y-ZZ, Rothwell JC, Lu C-SS, Chuang W-LL, Chen R-SS. Abnormal bidirectional plasticity-like effects in Parkinson's disease. Brain (2011) 134:2312-20. doi:10.1093/brain/awr158

114. Barbin L, Leux C, Sauleau P, Meyniel C, Nguyen J-M, Pereon Y, et al. Nonhomogeneous effect of levodopa on inhibitory circuits in Parkinson's disease and dyskinesia. Parkinsonism Relat Disord (2013) 19:165-70. doi:10.1016/j. parkreldis.2012.08.012

115. Sailer A, Molnar G, Paradiso G, Gunraj C, Lang A, Chen R. Short and long latency afferent inhibition in Parkinson's disease. Brain (2003) 126:1883-94. doi:10.1093/brain/awg183

116. Rolland A-SS, Herrero M-TT, Garcia-Martinez V, Ruberg M, Hirsch EC, François C. Metabolic activity of cerebellar and basal ganglia-thalamic neurons is reduced in Parkinsonism. Brain (2007) 130:265-75. doi:10.1093/brain/ awl337 
117. Takada M, Sugimoto T, Hattori T. MPTP neurotoxicity to cerebellar Purkinje cells in mice. Neurosci Lett (1993) 150:49-52. doi:10.1016/0304-3940(93) 90105- $\mathrm{T}$

118. Heman P, Barcia C, Gomez A, Ros CM, Ros-Bernal F, Yuste JE, et al. Nigral degeneration correlates with persistent activation of cerebellar Purkinje cells in MPTP-treated monkeys. Histol Histopathol (2012) 27:89-94.

119. Wu T, Hallett M. The cerebellum in Parkinson's disease. Brain (2013) 136:696-709. doi:10.1093/brain/aws360

120. Ni Z, Pinto AD, Lang AE, Chen R. Involvement of the cerebellothalamocortical pathway in Parkinson's disease. Ann Neurol (2010) 68:816-24. doi:10.1002/ana.22221

121. Helmich RC, Halett M, Deuschl G, Toni I, Bloem BR. Cerebral causes and consequences of parkinsonian rest tremor: a tale of two circuits? Brain (2012) 135:3206-26.

122. Hurtado JM, Gray CM, Tamas LB, Sigvardt KA. Dynamics of tremor-related oscillations in the human globus pallidus: a single case study. Proc Natl Acad Sci U S A (1999) 96:1674-9. doi:10.1073/pnas.96.4.1674

123. Amtage F, Henschel K, Schelter B, Vesper J, Timmer J, Lücking CH, et al. Tremor-correlated neuronal activity in the subthalamic nucleus of Parkinsonian patients. Neurosci Lett (2008) 442:195-9. doi:10.1016/j.neulet.2008.06.087

124. Berman B, Hallett M, Herscovitch P, Simonyan K. Striatal dopaminergic dysfunction at rest and during task performance in writer's cramp. Brain (2013) 136:3645-58. doi:10.1093/brain/awt282

125. Hubsch C, Roze E, Popa T, Russo M, Balachandran A, Pradeep S, et al. Defective cerebellar control of cortical plasticity in writer's cramp. Brain (2013) 136:2050-62. doi:10.1093/brain/awt147

126. Nimura T, Ando T, Yamaguchi K, Nakajima T, Shirane R, Itoh M, et al. The role of sigma-receptors in levodopa-induced dyskinesia in patients with advanced Parkinson disease: a positron emission tomography study. J Neurosurg (2004) 100:606-10. doi:10.3171/jns.2004.100.4.0606

127. Martin WJ, De Costa BR, Walker JM. Effects of sigma ligands on rat cerebellar Purkinje neuron firing: an iontophoretic study. Brain Res Bull (1994) 35:303-9. doi:10.1016/0361-9230(94)90106-6

128. Gronier B, Debonnel G. Involvement of sigma receptors in the modulation of the glutamatergic/NMDA neurotransmission in the dopaminergic systems. Eur J Pharmacol (1999) 368:183-96. doi:10.1016/S0014-2999(99)00025-4

129. Koch G, Brusa L, Carrillo F, Lo Gerfo E, Torriero S, Oliveri M, et al. Cerebellar magnetic stimulation decreases levodopa-induced dyskinesias in Parkinson disease. Neurology (2009) 73:113-9. doi:10.1212/WNL. 0b013e3181ad5387

130. Brusa L, Ceravolo R, Kiferle L, Monteleone F, Iani C, Schillaci O, et al. Metabolic changes induced by theta burst stimulation of the cerebellum in dyskinetic Parkinson's disease patients. Parkinsonism Relat Disord (2012) 18:59-62. doi:10.1016/j.parkreldis.2011.08.019

131. Hamada M, Strigaro G, Murase N, Sadnicka A, Galea JM, Edwards MJ, et al. Cerebellar modulation of human associative plasticity. J Physiol (2012) 590:2365-74. doi:10.1113/jphysiol.2012.230540

132. Dean P, Porrill J. The cerebellum as an adaptive filter: a general model? Funct Neurol (2010) 25:173-80.

133. Rascol O, Arnulf I, Paul H, Brefel-Courbon C, Vidailhet M, Thalamas C, et al. Idazoxan, an alpha-2 antagonist, and L-DOPA-induced dyskinesias in patients with Parkinson's disease. Mov Disord (2001) 16:708-13. doi:10.1002/ mds. 1143

134. Brooks D, Piccini P, Turjanski N, Samuel M. Neuroimaging of dyskinesia. Ann Neurol (2000) 47:S154-8; discussion S158-9.

135. Koch G, Brusa L, Caltagirone C, Peppe A, Oliveri M, Stanzione P, et al. rTMS of supplementary motor area modulates therapy-induced dyskinesias in Parkin- son disease. Neurology (2005) 65:623-5. doi:10.1212/01.wnl.0000172861. 36430.95

136. Brusa L, Versace V, Koch G, Iani C, Stanzione P, Bernardi G, et al. Low frequency rTMS of the SMA transiently ameliorates peak-dose LID in Parkinson's disease. Clin Neurophysiol (2006) 117:1917-21. doi:10.1016/j.clinph.2006.03.033

137. Filipovic S, Rothwell J, Warrenburg B, Bhatia K. Repetitive transcranial magnetic stimulation for levodopa-induced dyskinesias in Parkinson's disease. Mov Disord (2009) 24:246-53. doi:10.1002/mds.22348

138. Payoux P, Remy P, Damier P, Miloudi M, Loubinoux I, Pidoux B, et al. Subthalamic nucleus stimulation reduces abnormal motor cortical overactivity in Parkinson disease. Arch Neurol (2004) 61:1307-13. doi:10.1001/archneur.61.8. 1307

139. Castrioto A, Lhommée E, Moro E, Krack P. Mood and behavioural effects of subthalamic stimulation in Parkinson's disease. Lancet Neurol (2014) 13:287-305. doi:10.1016/S1474-4422(13)70294-1

140. Xu W, Russo G, Hashimoto T, Zhang J, Vitek J. Subthalamic nucleus stimulation modulates thalamic neuronal activity. J Neurosci (2008) 28(46):11916-24. doi:10.1523/JNEUROSCI.2027-08.2008

141. Kim H-JJ, Paek SH, Kim J-YY, Lee J-YY, Lim YH, Kim DG, et al. Twoyear follow-up on the effect of unilateral subthalamic deep brain stimulation in highly asymmetric Parkinson's disease. Mov Dis (2009) 24:329-35. doi:10.1002/mds.22211

142. Wagle Shukla A, Moro E, Gunraj C, Lozano A, Hodaie M, Lang A, et al. Long-term subthalamic nucleus stimulation improves sensorimotor integration and proprioception. J Neurol Neurosurg Psych (2013) 84:1020-8. doi:10.1136/jnnp-2012-304102

143. Kishore A, Panikar D, Balakrishnan S, Joseph S, Sarma S. Evidence of functional somatotopy in GPi from results of pallidotomy. Brain (2000) 123(Pt 12):2491-500. doi:10.1093/brain/123.12.2491

144. Krack P, Pollak P, Limousin P, Hoffmann D, Benazzouz A, Bas J, et al. Opposite motor effects of pallidal stimulation in Parkinson's disease. Ann Neurol (1998) 43:180-92. doi:10.1002/ana.410430208

145. Sidibé M, Paré J-FF, Smith Y. Nigral and pallidal inputs to functionally segregated thalamostriatal neurons in the centromedian/parafascicular intralaminar nuclear complex in monkey. J Comp Neurol (2002) 447:286-99. doi:10.1002/ cne. 10247

146. Stefani A, Peppe A, Pierantozzi M, Galati S, Moschella V, Stanzione P, et al. Multi-target strategy for Parkinsonian patients: the role of deep brain stimulation in the centromedian-parafascicularis complex. Brain Res Bull (2009) 78:113-8. doi:10.1016/j.brainresbull.2008.08.007

Conflict of Interest Statement: The authors declare that the research was conducted in the absence of any commercial or financial relationships that could be construed as a potential conflict of interest.

Received: 30 June 2014; accepted: 05 August 2014; published online: 18 August 2014. Citation: Kishore A and Popa $T$ (2014) Cerebellum in levodopa-induced dyskinesias: the unusual suspect in the motor network. Front. Neurol. 5:157. doi: 10.3389/fneur.2014.00157

This article was submitted to Movement Disorders, a section of the journal Frontiers in Neurology.

Copyright ( $) 2014$ Kishore and Popa. This is an open-access article distributed under the terms of the Creative Commons Attribution License (CC BY). The use, distribution or reproduction in other forums is permitted, provided the original author (s) or licensor are credited and that the original publication in this journal is cited, in accordance with accepted academic practice. No use, distribution or reproduction is permitted which does not comply with these terms. 